\title{
Determination of Processed Salmon Components Sticking to Polyethylene Terephthalate Coatings of Containers by FT-IR and Raman Vibrational Spectroscopy
}

\author{
E. Zumelzu $\left(\mathbb{D},{ }^{1}\right.$ A. Sanz, ${ }^{2}$ J. Medina, ${ }^{2}$ and F. Rull ${ }^{2}$ \\ ${ }^{1}$ Institute of Materials, Austral University of Chile, P.O. Box 567, 5111187 Valdivia, Chile \\ ${ }^{2}$ Department of Condensed Matter Physics, University of Valladolid, 47002 Valladolid, Spain \\ Correspondence should be addressed to E. Zumelzu; ezumelzu@uach.cl
}

Received 26 January 2018; Accepted 20 March 2018; Published 19 April 2018

Academic Editor: Renata Diniz

Copyright (c) 2018 E. Zumelzu et al. This is an open access article distributed under the Creative Commons Attribution License, which permits unrestricted use, distribution, and reproduction in any medium, provided the original work is properly cited.

\begin{abstract}
Earlier studies determined that portions of salmon were strongly sticking to the polymer coating of the container walls after emptying the cans. In this sense, this work performed high- and low-frequency spectral characterizations of fresh salmon muscle, fat, and skin by Fourier-transform infrared (FT-IR) and Raman spectroscopy analyses to elucidate which components were effectively sticking to the underlying coating. The spectral analyses evidenced that the bands of skin and muscle were clearly distinctive. However, less perceptible contrasts were observed between fat and muscle until band $1700 \mathrm{~cm}^{-1}$, but above this limit, the minor spectral changes detected were sufficient to characterize both salmon components. The new spectral bands for skin occurred at 1030,1202, and $1336 \mathrm{~cm}^{-1}$. Differences in intensity were also observed for band $v(\mathrm{C}=\mathrm{O})$ at $1744 \mathrm{~cm}^{-1}$, even though it appeared in all components of the salmon. The bands for the $v(\mathrm{C}-\mathrm{H})$ and $v(\mathrm{O}-\mathrm{H})$ vibrations in the high-frequency region were the same, but the intensities and profiles were different. The similarities between the spectra of fresh salmon muscle and residues sticking to the polymer layers were substantial, corroborating that this is in fact the main component sticking to the polymer surface coating of industrial food cans.
\end{abstract}

\section{Introduction}

Vibrational spectroscopy is a useful and well-recognized technique to investigate the changes in chemical composition and molecular structure of proteins, carbohydrates, nucleic acids, cell membranes, and tissues. Molecular vibrations are defined as infrared (IR) active when the dipolar momentum of the molecule changes as the molecule vibrates, whereas vibrations are considered Raman active when the polarizability of the molecule changes as the molecule vibrates [1-3]. On the other hand, one of the main reasons for using Raman is that the spectrum delivers a structural fingerprint of the molecules analyzed. This has been evident with the development of surface-sensitive techniques for molecular analysis such as the surface-enhanced Raman spectroscopy (SERS), a highly sensitive method to detect nucleic acids, analytes, cells, and tissues [4].
The advance of other modern instrumental techniques based on vibrational, visible, near-infrared (NIR), midinfrared (MIR), and Raman spectroscopy has led to a variety of applications in the food and beverage industry, especially in the alcoholic beverage industry [5]. Lately, analytical tools such as Raman spectroscopy and FT-IR have also been employed as useful noninvasive techniques given the global interest in food quality, production, and safety and have been shown suitable for practical use in food research [6]. In fact, there have been developments in the analysis of fish oils prone to oxidation and in the study of structural changes of fish proteins during comminution and gelation $[7,8]$.

Thus, vibrational spectroscopy techniques and especially Fourier-transform infrared (FT-IR) and Raman are nondestructive and noninvasive valuable characterization methods to elucidate material compositions, molecular structural changes, and environmental effects on biological and 
engineering materials in a variety of applications of the aquaculture industry [9-16].

Earlier studies in this research line have evaluated a composite consisting of a multilayered electrolytic chromiumcoated steel (ECCS) laminate protected by a polyethylene terephthalate (PET) coating employed in salmon canning. The sticking of postmortem salmon to the container wall surface protected by PET and the effects on the polymer coating were studied, with a special focus on its degradation and hence on its use as a recyclable input in other applications [17]. Other works have established the presence of compounds in the diet of salmons and the existence of peptides that adhere to the PET polymer, leading to changes in the color of the container walls thus affecting the consumer's visual perception of quality [18].

The aforementioned studies have made evident the strong sticking and adherence of salmon muscles to the polymer and the influence of its degree of freshness and oxidation on the PET coating of the container, among other aspects. In addition, another work evaluated the effects of thermal sterilization of food containers and storage on muscle degradation inside the food can and considered all the muscle deposits on the polymer layer. Morphological characterizations by scanning electron microscopy (SEM) were also performed, but a thorough discrimination by vibrational spectroscopy to determine whether the sticking product was either muscle, fat, or skin residues or a combination of them was not fully done.

Thus, the present work is an original research aimed at determining by vibrational techniques that the material sticking to the polymer surface consists, indeed, of salmon muscle. Therefore, we will compare the results from earlier works for canned salmon muscle adhered to the polymer surface of container walls with fresh muscle, fat, and skin by FT-IR and Raman analyses.

This comparison is important both for the efficient discrimination of salmon muscle as the fraction sticking to the container and for highlighting the characterization techniques as useful tools to analyze the interactions between biological materials and industrial polymers employed in food containers, since the quality of products involves not only the production processes but also the correct identification of fish products.

\section{Materials and Methods}

The abovementioned studies cited in References were performed in metal-polymer containers consisting of a PET coating protecting an ECCS plate with an average thickness of $0.20 \mathrm{~mm}$; the chemical composition (\%wt) of steel in these samples was $0.074 \% \mathrm{C}, 0.260 \% \mathrm{Mn}, 0.021 \% \mathrm{P}, 0.016 \% \mathrm{~S}$, $0.012 \% \mathrm{Si}, 0.032 \% \mathrm{Al}, 45 \mathrm{ppm} \mathrm{N}$, and Fe (remaining percentage). The steel plate was coated by a layer generated by electrolytic deposition and consisted of a $0.01 \mu \mathrm{m}$ thick chromium $\left(\mathrm{Cr}^{0}\right)$ and chromium oxide $\left(\mathrm{Cr}_{2} \mathrm{O}_{3}\right)$ with an average thickness of $0.01 \mu \mathrm{m}$ and a total chromium content of $101.33 \mathrm{mg} / \mathrm{m}^{2}$. This ECCS plate had a $30 \mu \mathrm{m}$ thick protective layer of PET formed by polymerized units of dimethyl terephthalate and ethylene glycol.
The main components of canned salmon are muscle, fat, and a minimum portion of skin. The muscle has a fibrillar morphology, the fat is homogeneous, and the skin is grey and scaly, being easy to characterize by microscopy observations; we are especially interested in contrasting these observations with vibrational spectroscopy analyses to validate the accuracy of the characterization techniques [17].

Several samples from recently captured salmon specimens and of the same type than those employed for canning purposes by an aquaculture plant from Puerto Montt, Chile, were selected. The muscle, fat, and skin were separately analyzed, and their spectra were compared to earlier results from salmon residues sticking to container walls.

The samples were characterized using the analytical and structural techniques FT-IR and micro-Raman spectroscopy. The IR spectra were measured on different spots in the XY position with a Perkin Elmer Spectrum 100 FT-IR spectrometer supplied with a Universal ATR Sampling Accessory. These points were very close to those considered for Raman spectroscopy analyses in order to establish differences or similarities between the results of both techniques.

The micro-Raman analyses employed two backilluminated fiber-coupled spectrometers featuring $633 \mathrm{~nm}$ and $785 \mathrm{~nm}$ wavelengths. The experiment considered mainly the data acquired at $785 \mathrm{~nm}$. This device consisted of a multimode fiber laser BWTEK BRM-OEM-785 (785 nm), a Raman head BWTEK BAC100-785E, and an objective lens Zeiss Epiplan 50x/0.50 infinite/0 442850 with a focal length of $6.5 \mathrm{~mm}$. The maximum output of the laser through this lens was approximately $165 \mathrm{~mW}$; the laser spot diameter measured on the samples was 48 microns.

The Raman spectrometer was a BWTEK Prime $\mathrm{T}$ BTC661E-785CUST, covering a spectrum in the range 0$3000 \mathrm{~cm}^{-1}$, with a spectral resolution of $5 \mathrm{~cm}^{-1}$, and a CCD Hamamatsu S10141-1107S operating at $-10^{\circ} \mathrm{C}$.

In addition, the analyses employed a WITec's alpha300 R confocal Raman imaging microscope, featuring a $785 \mathrm{~nm}$ wavelength laser, operated with an ultra-high-throughput spectrometer (UHTS), and accommodating VIS-NIR wavelengths with a sensitivity of 530-1100 nm.

\section{Results and Discussion}

The FT-IR spectra depicted in Figure 1 correspond to fresh salmon muscle samples exhibiting various degrees of flesh colors with the purpose of establishing their relevant spectral features and were compared with deposits adhered to the PET polymer coating of food cans.

No important spectral variations were observed in the intensity and width of peaks for bands up to $3500 \mathrm{~cm}^{-1}$ regarding this component of salmon. The characterization was well-defined, and thus it was selected as a control for the fresh salmon muscle.

Figure 2 considers the most representative spectra of the series of tests performed for the characterization of fat from fresh salmon samples.

The FT-IR analyses showed certain wavelength similarities between salmon fat and muscle until band $1700 \mathrm{~cm}^{-1}$; 


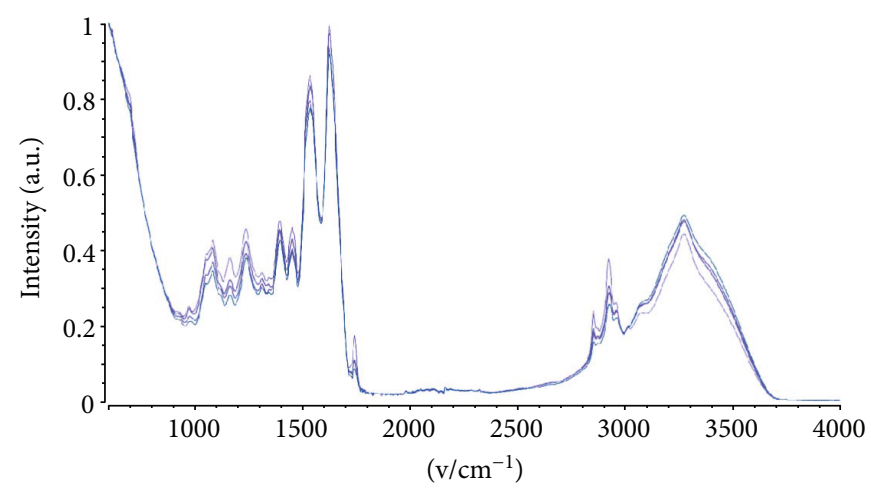

FIGURE 1: FT-IR spectra of fresh salmon muscle sampled from areas exhibiting two distinctive flesh colors: brown and pink.

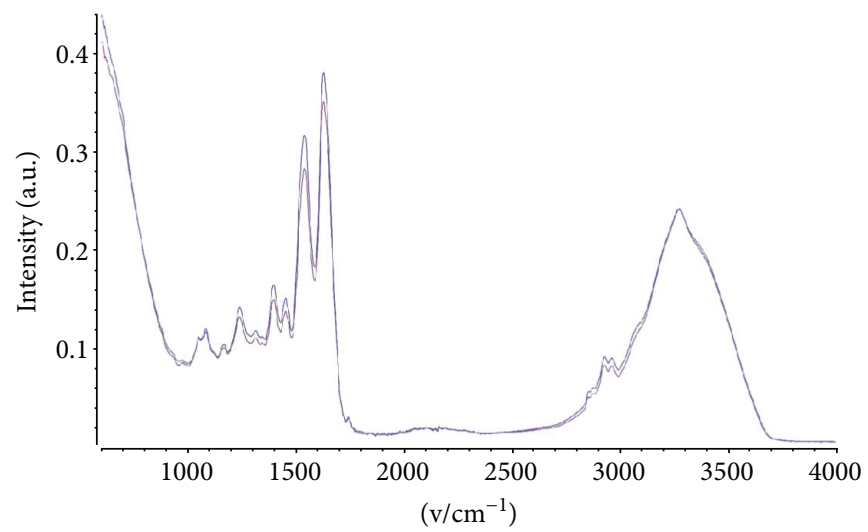

FIgURE 2: FT-IR spectra of fat from fresh salmon samples displaying a broad range of bandwidths.

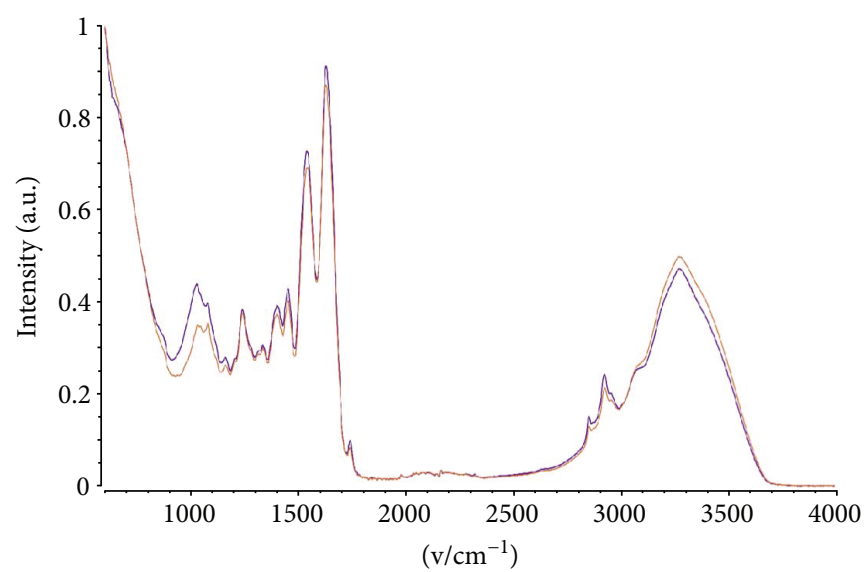

FIGURE 3: FT-IR spectra of the outer skin surface from fresh salmon sampled on two different spots.

however, above this limit, there were minor spectral changes but enough to differentiate both components.

In turn, Figures 3 and 4 characterize the skin of fresh salmon; no significant spectral changes can be observed when comparing the spectra to those in Figures 1 and 2.

The analyses of spectra from salmon skin samples showed no evidence of variations in characterization on both the outer and inner surfaces, and their composition was homogeneous with no presence of contaminants or environmental effects on them before canning.
The whole set of former analyses was made to compare the spectra of all components of fresh salmon and superimpose the plots in such a way as to visualize any differences based on the wavelength bands studied and represented in Figure 5.

From these results, it is possible to say that the spectra are slightly different, depending on the salmon component examined, but every component under study showed very homogeneous spectra. This is highly positive when trying to identify which component of salmon effectively adheres 


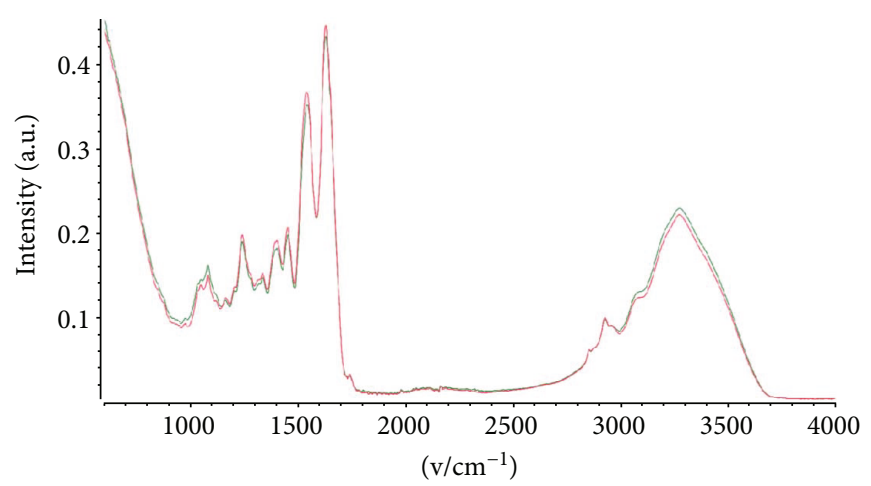

FIgURE 4: FT-IR spectra of the inner skin surface from fresh salmon samples.

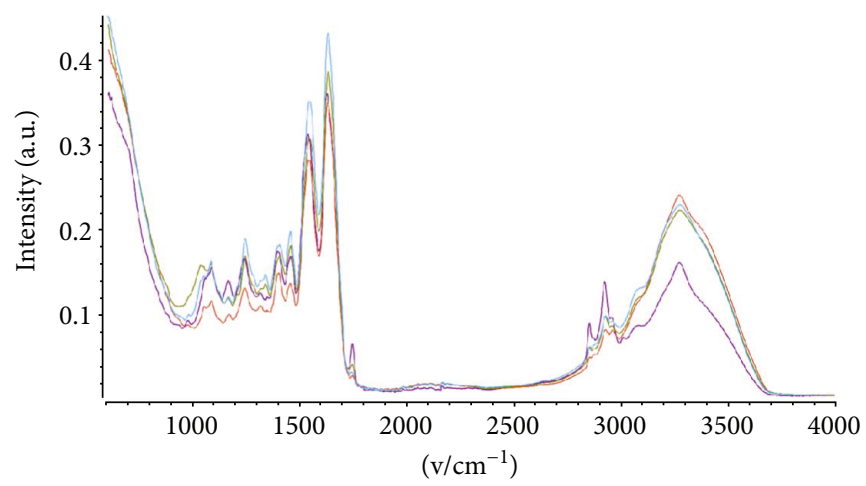

FIGURE 5: FT-IR spectral comparison of the different fresh salmon components. Brown spectrum belongs to salmon muscle, red spectrum to fat, and dark and light green to the outer and inner skin surfaces, respectively.

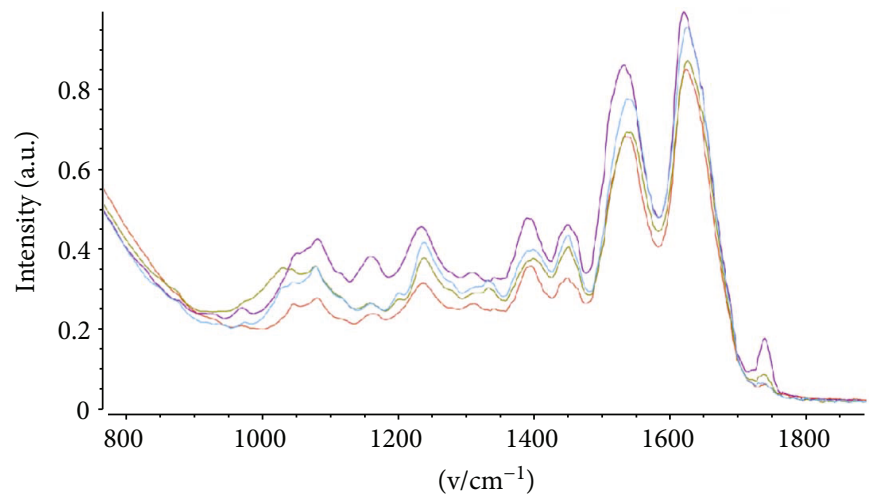

Figure 6: Comparison of low-frequency FT-IR spectra of different fresh salmon components.

to the polymer coating and thereby validates studies already performed and cited in References of this work [17, 18]. The following figures detail the regions of interest for comparison purposes. Thus, it can be seen from the lowfrequency spectra in Figure 6 that the dissimilar bands are produced mainly by the salmon skin and muscle, whereas there are hardly any differences between those of fat and muscle. The skin shows new bands at 1030, 1202, and $1336 \mathrm{~cm}^{-1}$. Differences in intensity are also observed for band $v(\mathrm{C}=\mathrm{O})$ at $1744 \mathrm{~cm}^{-1}$, although it appears in all components of the salmon.
Figure 7 shows that the bands for the $v(\mathrm{C}-\mathrm{H})$ and $v(\mathrm{O}-\mathrm{H})$ vibrations located in the high-frequency region are the same, but the intensities and profiles are different.

The second step of this study consisted of a comparison between the spectra from regions that in our former studies had shown a reduced or very low contamination by salmon adhered to the PET layer [17] and the salmon spectra individually characterized in this work.

As it can be noticed in Figure 8, the spectra from areas of salmon adherence to the PET polymer match well with those from fresh salmon muscle. It can also be seen that 




FIgURE 7: Comparison of high-frequency FT-IR spectra of different fresh salmon components.

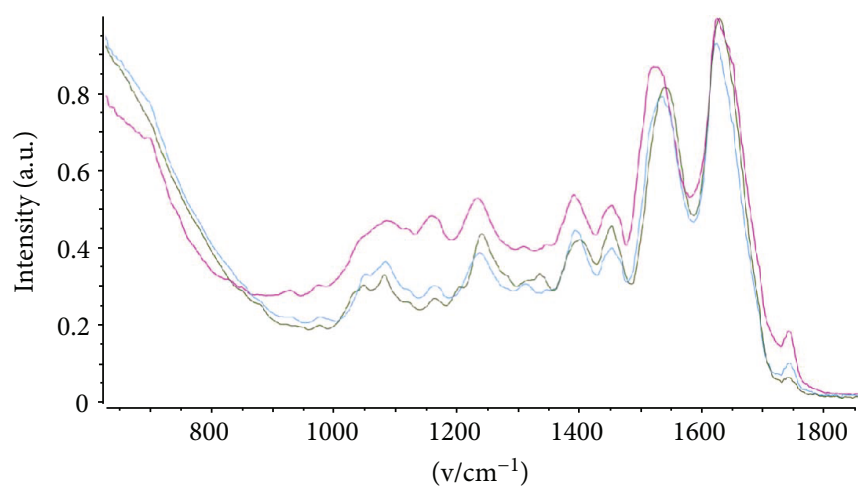

Figure 8: Comparison between the low-frequency FT-IR spectra of surface polymer coatings from areas of salmon adherence (pink spectrum) and those of salmon muscle (light blue spectrum) and skin (green spectrum).

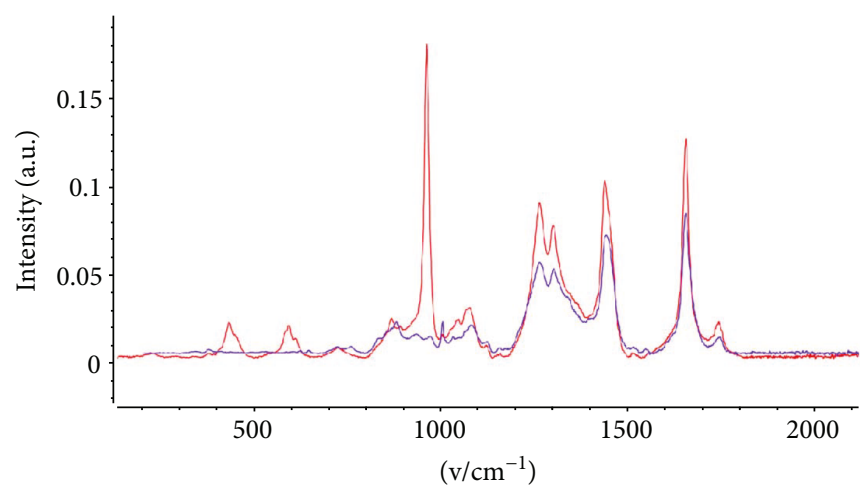

FIGURE 9: Raman spectra of salmon muscle deposits adhered to the food container walls (blue) and fresh salmon muscle (red).

the adherence spectra show wider bands than those of fresh salmon, and the amide II band located at $1544 \mathrm{~cm}^{-1}$ in fresh salmon clearly shifts to $1525 \mathrm{~cm}^{-1}$ in adhered salmon. This indicates a degradation of salmon in contact with the polymer coating due to the thermal treatment undergone during the canning process.

Regarding the Raman spectroscopy analyses and characterizations made during this validation study, Figure 9 gives details of the comparison between salmon residues adhered to the PET polymer surface [17] and fresh salmon muscle.

The Raman spectra for both types of samples are similar, confirming the earlier results obtained by FT-IR analyses.

\section{Conclusions}

A comprehensive original study of fresh salmon components, that is, muscle, fat, and skin, was performed by vibrational spectroscopy evaluations in order to compare and validate earlier studies on residual salmon deposits adhered to PET polymer coatings of ECCS plates, leading to changes in the appearance of the protective layers and limiting their recycling potential as ecomaterials.

The results allowed us to elucidate that the main residue that adhered to the container walls of food cans consisted in fact of salmon muscle, given the correspondence between the 
low-frequency FT-IR and Raman spectral analyses from fresh and canned samples.

The techniques employed are powerful and straightforward tools to validate these analyses when compared to other methods such as electron microscopy studies that require further preparation of biological samples, and secondarily, they have a valuable contribution to quality control processes in food safety inspections.

\section{Conflicts of Interest}

The authors declare that they have no conflicts of interest.

\section{Acknowledgments}

The authors gratefully acknowledge the FONDECYT program of CONICYT Chile for the financial support through Grant no. 1130634, the FONDEQUIP program of CONICYT Chile for the financial support in the acquisition of equipment code no. EQM 160050, and the special contributions of the Austral University of Chile and University of Valladolid in Spain.

\section{References}

[1] R. J. Swain and M. M. Stevens, "Raman microspectroscopy for non-invasive biochemical analysis of single cells," Biochemical Society Transactions, vol. 35, no. 3, pp. 544-549, 2007.

[2] A. S. Sivam, D. Sun-Waterhouse, C. O. Perera, and G. I. N. Waterhouse, "Application of FT-IR and Raman spectroscopy for the study of biopolymers in breads fortified with fibre and polyphenols," Food Research International, vol. 50, no. 2, pp. 574-585, 2013.

[3] J. Felten, H. Hall, J. Jaumot, R. Tauler, A. de Juan, and A. Gorzsás, "Vibrational spectroscopic image analysis of biological material using multivariate curve resolution alternating least squares (MCR-ALS)," Nature Protocols, vol. 10, no. 2, pp. 217-240, 2015.

[4] A. F. Chrimes, K. Khoshmanesh, P. R. Stoddart, A. Mitchell, and K. Kalantar-zadeh, "Microfluidics and Raman microscopy: current applications and future challenges," Chemical Society Reviews, vol. 42, no. 13, pp. 5880-5906, 2013.

[5] R. Schalk, D. Geoerg, J. Staubach, M. Raedle, F. J. Methner, and T. Beuermann, "Evaluation of a newly developed mid-infrared sensor for real-time monitoring of yeast fermentations," Journal of Bioscience and Bioengineering, vol. 123, no. 5, pp. 651-657, 2017.

[6] A. Nawrocka and J. Lamorska, "Determination of food quality by using spectroscopic methods," in Chapter 14, Agricultural and Biological Sciences, Advances in Agrophysical Research, S. Grundas and A. Stepniewski, Eds., Intech, Croatia, 2013.

[7] D. P. Killeen, S. N. Marshall, E. J. Burgess, K. C. Gordon, and N. B. Perry, "Raman spectroscopy of fish oil capsules: polyunsaturated fatty acid quantitation plus detection of ethyl esters and oxidation," Journal of Agricultural and Food Chemistry, vol. 65, no. 17, pp. 3551-3558, 2017.

[8] Y. Kobayashi, S. G. Mayer, and J. W. Park, "FT-IR and Raman spectroscopies determine structural changes of tilapia fish protein isolate and surimi under different comminution conditions," Food Chemistry, vol. 226, pp. 156-164, 2017.
[9] H. Henmi, M. Hata, and M. Takeuchi, "Studies on the carotenoids in the muscle of salmon-V. Combination of astaxanthin and canthaxanthin with bovine serum albumin and egg albumin," Comparative Biochemistry and Physiology Part B: Comparative Biochemistry, vol. 99, no. 3, pp. 609-612, 1991.

[10] R. Schweitzer-Stenner, T. Measey, A. Hagarman, F. Eker, and K. Griebenow, "Salmon calcitonin and amyloid $\beta$ : two peptides with amyloidogenic capacity adopt different conformational manifolds in their unfolded states," Biochemistry, vol. 45, no. 9, pp. 2810-2819, 2006.

[11] J. H. Cheng, Q. Dai, D. W. Sun, X. A. Zeng, D. Liu, and H. B. $\mathrm{Pu}$, "Applications of non-destructive spectroscopic techniques for fish quality and safety evaluation and inspection," Trends in Food Science \& Technology, vol. 34, no. 1, pp. 18-31, 2013.

[12] N. K. Afseth, M. Bloomfield, J. P. Wold, and P. Matousek, "A novel approach for subsurface through-skin analysis of salmon using spatially offset Raman spectroscopy (SORS)," Applied Spectroscopy, vol. 68, no. 2, pp. 255-262, 2014.

[13] J. L. Xu, C. Riccioli, and D. W. Sun, "An overview on nondestructive spectroscopic techniques for lipid and lipid oxidation analysis in fish and fish products," Comprehensive Reviews in Food Science and Food Safety, vol. 14, no. 4, pp. 466-477, 2015.

[14] T. Jiao, N. Krstulović, B. Wu, X. Chen, and Q. Zhang, "Spectroscopy in materials chemistry," Journal of Spectroscopy, vol. 2015, Article ID 943894, 2 pages, 2015.

[15] B. Raskovic, R. Heinke, P. Rösch, and J. Popp, "The potential of Raman spectroscopy for the classification of fish fillets," Food Analytical Methods, vol. 9, no. 5, pp. 1301-1306, 2016.

[16] J. Hikima, M. Ando, H. Hamaguchi et al., "On-site direct detection of astaxanthin from salmon fillet using Raman spectroscopy," Marine Biotechnology, vol. 19, no. 2, pp. 157-163, 2017.

[17] E. Zumelzu, M. J. Wehrhahn, F. Rull, H. Pesenti, O. Muñoz, and R. Ugarte, "Evaluation of salmon adhesion on PETmetal interface by ATR, FT-IR, and Raman spectroscopy," Journal of Spectroscopy, vol. 2015, Article ID 835798, 7 pages, 2015.

[18] E. Zumelzu, M. J. Wehrhahn, F. Rull, H. Pesenti, O. Muñoz, and R. Ugarte, "Effect of the degree of muscle oxidation on sticking and degradation of polyethylene terephthalate (PET) layers in electrolytic chromium coated steels," Journal of Coatings Technology and Research, vol. 14, no. 3, pp. 673682, 2017. 

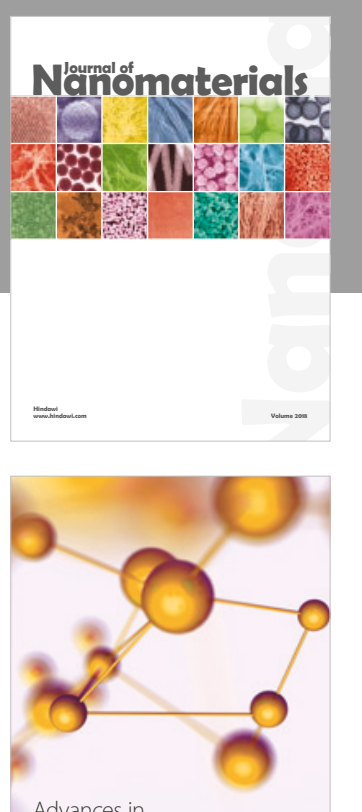

Physical Chemistry
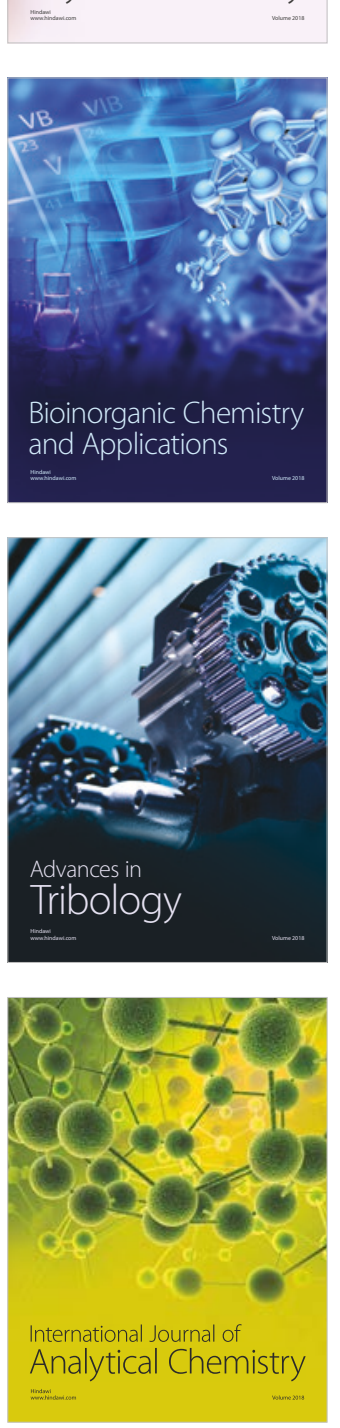

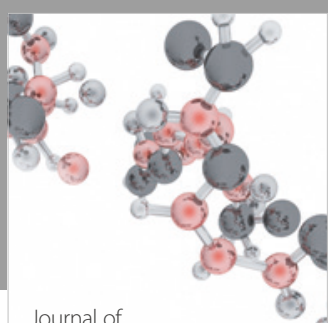

Analytical Methods

in Chemistry



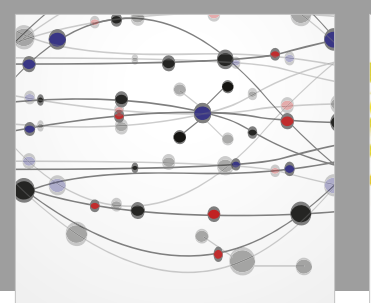

The Scientific World Journal

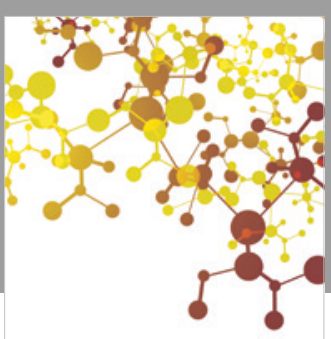

Journal of

Applied Chemistry
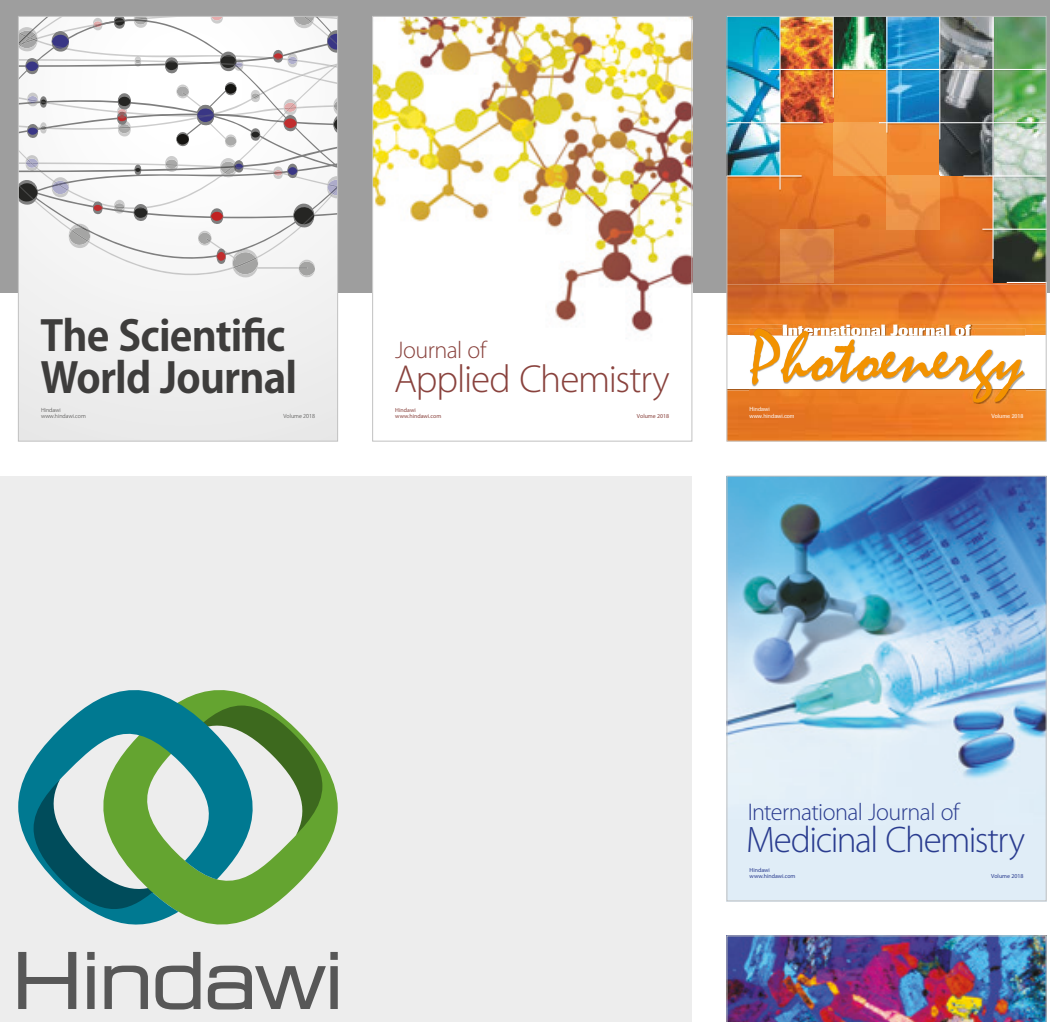

Submit your manuscripts at

www.hindawi.com
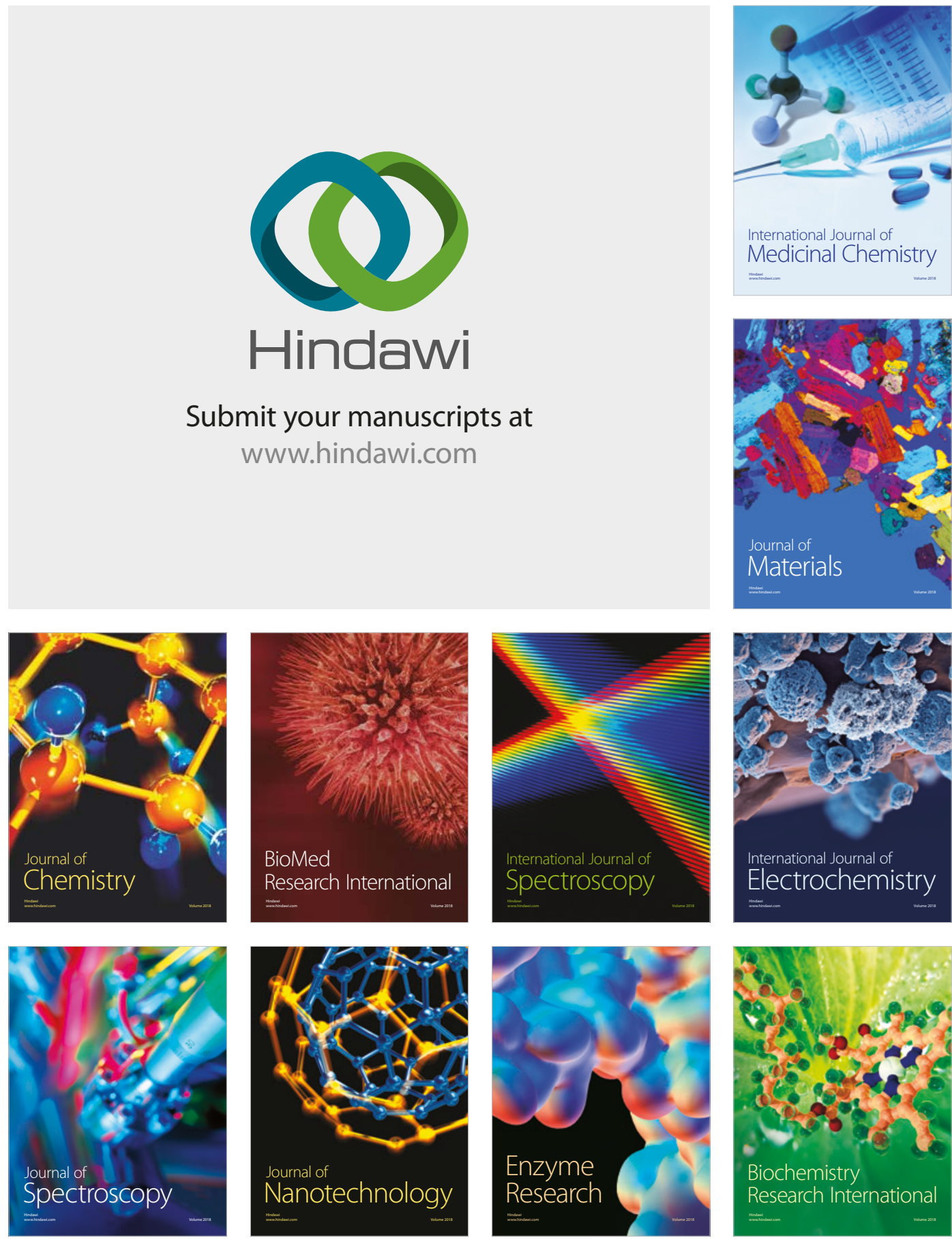
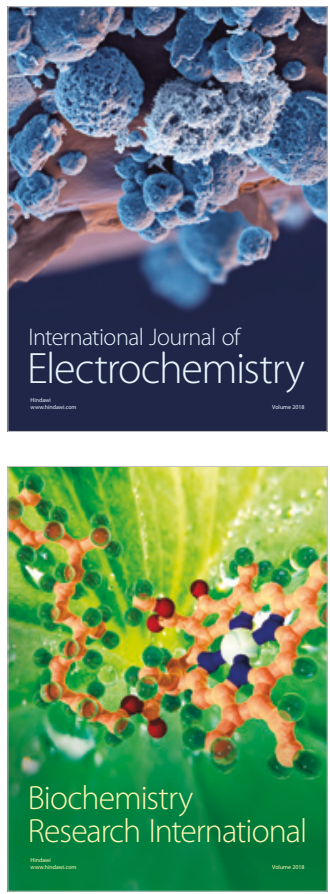